\title{
Strategy of Promoting Outward Investment under “One Belt One Road” : Empirical Evidence from Fujian Province
}

\author{
Shan Shan Wang ${ }^{1,}$, , Yang Jing ${ }^{2}$ \\ ${ }^{1,2}$ Xiamen University of Technology, No.600 Ligong Road, Jimei District, Xiamen, 361024, Fujian \\ Province, China \\ awangshanshan@xmut.edu.cn
}

\begin{abstract}
Keywords: enterprises; OFDI; gravity model; influencing factors
Abstract. This paper employs the gravity model to discuss the influencing factors of OFDI in Fujian enterprises. The research results are as follows under the impact of globalization, enterprises in Fujian,the development of outward direct investment satisfies their own needs; distance have negative effect on enterprises in Fujian's OFDI.Fujian enterprises tend to invest in neighboring areas; appreciation of the currency exchange rate is conducive to the increase of outward direct investment; Fujian enterprises have a clear motivation to seek strategic resources; language environment and colonial history are also related to the location choice of OFDI of Fujian Province.
\end{abstract}

\section{Introduction}

In recent years, with the continuous improvement of China's comprehensive strength, the proportion of outward foreign direct investment is also growing. During 2002 and 2015, China's outward foreign direct investment flows have a rapid upward trend. Until 2015, Chinese foreign direct investment flows to a record high of $\$ 145.67$ billion, an increase of $18.3 \%$, surpassed Japan to become the world's second largest foreign investment country; China's 20200 domestic enterprises have set up 30800 foreign direct investment enterprises abroad, which are distributed in 188 countries (regions); The investment area was highly concentrated, the investment of "The Belt and Road " nations increasing rapidly.

\section{Literature review}

In terms of the empirical study of the motivation in OFDI, one of the most important research methods is to construct an investment gravity model to explain the driving factors of OFDI. Gravity models were first used in natural science to express the concept of gravity between two substances that are attracted by each other. The magnitude of gravity is in direct proportion to to the product of the masses of two substances and in inverse proportion the square of the distance. Tinbergen used gravity model for the first time to study bilateral trade in 1962.After that, in the study of international investment, the gravity model have been widely used. Anderson (1979) applies gravity models to the field of related research of FDI and then the initial FDI model formula is established. With the development of China' s OFDI, the distribution of its location has also aroused widely concern in the academic circle. Buckley, Clegg, Cross and Liu (2007) build investment gravity model to investigate China outward foreign direct investment in 49 countries by using yearly data from 1984 to 2001.The empirical results show that China's outward foreign direct investment first has the motivation to seek the market, and is in direct proportion to to bilateral trade, cultural proximity and host country inflation, and is negatively related to the host country system. The application of gravity model in domestic and foreign investment mainly focuses on China's outward foreign direct investment. Cheng Huifang and Ruan Xiang (2004) also employ the investment gravity model to analyze the data on China's OFDI in 32 countries. It is found that China's OFDI is positively related to the per capital income of the host country and the market size. Wen Jieli (2010) carries on the weighted least squares regression analysis by using the data of Jiangsu Province in 2007, it is found that the influencing factors of OFDI in Jiangsu province include market size, tariff level and trade links. It also proves that the OFDI in Jiangsu Province non market seeking model, it has the nature of avoiding tariff barriers 
and seeking the complement of strategic resources and trade[. In addition, Jiang Guanhong and Jiang Dianchun (2012) use empirically test China's OFDI by using the data of 95 countries, they argue that China's OFDI is positively related to China's economic scale, the size of the host country market, the concentration of resources, and the strategic assets, and negatively related to the distance factor. In addition, China's OFDI has a positive impact on the system quality and wage level of the host country, but it is not very important .

In comparison to previous studies, this paper try to employ investment gravity to research status and difficulties of enterprises in Fujian by collecting relevant data. It's worth mentioning that the construction of investment attraction model can more clearly by data analysis the influence factors of outward foreign direct investment of Fujian enterprises. Finally, based on the results of empirical analysis, this paper puts forward more practical, targeted policy implications. This will help promote the development of Fujian enterprises themselves and raise the degree of OFDI in Fujian Province, which will be of great significance to the promotion of China's outward foreign investment and the level of opening to the outside world.

\section{Current Situation of Fujian Enterprises' OFDI}

The outward foreign direct investment of Fujian enterprises has a certain foundation, and develop very rapidly but started late. What' s more, its industries are mainly small scale and low value-added. In addition private enterprises as the main force of investment, whose target of outward foreign direct investment concentrated in Fuzhou, Xiamen, Quanzhou.ASEAN countries have become a hot investment destination. At the same time, poor ability to resist risks, lack of talent and financing difficulties are the problems faced by enterprises in Fujian

Fujian enterprises are generally small and medium enterprises, most of the enterprises are processing and manufacturing industry. In the short term, low value-added industries such as trade and processing enterprises have the advantages in private enterprises in Fujian. But in the long run, low value-added and labor-intensive industries make it difficult for enterprises to bring long-term international competitive advantages, and it is difficult to bring effective help to optimize the industrial structure in Fujian. The main purpose of this kind of foreign investment activities is to seek cheap labor force and sell excess domestic production. The demand for high value-added investment funds is too large for the general enterprises.

Represented by Quanzhou, private enterprises play an important role in OFDI in Fujian. With the continuous development of private enterprises in Fujian and private economy, many private enterprises expect to go abroad, to carry out foreign direct investment, the emergence of Zijin Mining, Fuyao, Wanli Stone and a number of large enterprises have become the main force of Fujian OFDI. Fuzhou is the capital city of Fujian, Xiamen is an important port for foreign trade, and Quanzhou is a concentrated area of private enterprises. The main reason for the leading outward foreign direct investment of these three cities lies in the relatively strong private economic, the export-oriented consciousness of enterprises is more prominent, and the economic development is more dependent on the international market.

As a result of similar customs, similar language, culture economic policy and complementary industries, ASEAN countries has become a popular destination for Fujian enterprises to invest overseas. In 2014, Fujian's newly approved investment in ASEAN was \$210 million, an increase of 93.67\%.By the end of 2015, Fujian had set up 223 overseas enterprises and branches in the ASEAN region, the stock of outward foreign investment amounted to $\$ 2.7$ billion, distributed in 10 ASEAN countries. ASEAN has become the second largest outward foreign direct investment destination in Fujian.

\section{The Influencing Factors of Fujian Enterprises' Outward Foreign Direct Investment}

How to resolve the problems of OFDI in Fujian enterprises, we need to further analyze the influencing factors of OFDI in Fujian Enterprises. This paper will build an investment gravity model to study the impact of outward foreign direct investment in Fujian enterprises. Establish the multiple 
linear regression model of Fujian OFDI with Fujian provincial market economy scale, the market size of host country, host country strategic resources, exchange rate, language environment and colonial history.

\section{Model Setting}

In this paper, the gravity model is used to study the location factors of OFDI.The original investment gravity model (Anderson, 1970) is properly transformed to test the variables required for the study, at the same time, referring to the study of Jiang Guanhong and Jiang Dianchun (2012), the model is set as follows:

$$
\begin{aligned}
& \ln (\text { OFDI })_{g t}=\omega_{0}+\omega_{1} \ln (\text { fgdp })_{t}+\omega_{2} \ln (\text { cgdp })_{g t}+\omega_{3} \ln (\text { distance })_{g}+\omega_{4} \ln (\text { exch })_{g t} \\
& +\omega_{5} \ln (\text { coll })_{g t}+\omega_{6} \ln (\text { pat })_{g t}+\omega_{7} \ln (\text { landoff })_{g}+\omega_{8} \ln (\text { colon })_{g}+\varepsilon_{g t}
\end{aligned}
$$

In model (1), g represents the host country and $t$ represents the time. OFDI is the direct investment flows of Fujian enterprises to host countries. fgdp is the GDP of Fujian Province, which indicates the market scale of Fujian province; cgdp is the host country's GDP, which represents the market size of the host country; distance is the distance between China and the host country, indicating the distance cost of investment; exch is the exchange rate of the euro against the host countries. $\omega_{0}$ is a constant, $\varepsilon_{\mathrm{g} t}$ is the residual term. According to the theoretical hypothesis, the main controlling variables are the strategic assets of the host country, the linguistic environment and the colonial situation.

\section{Statistical Description}

Combining the expanded gravity model and the requirements analyzed in this paper, the explained variable we set is outward foreign direct investment flows of Fujian Province. The explanatory variable is the Fujian' s GDP, the host countries' GDP, the geographical distance between Fujian and the host country, and the exchange rate of RMB against each host country currency. The control variables are the gross enrollment rate of each host university, the total number of patent applications, the use of Chinese in the host country and the colonial history of the host country (see Table 1)

\begin{tabular}{|c|c|c|c|c|c|c|}
\hline & Variable & Describe & Mean & $\begin{array}{l}\text { Standard } \\
\text { Deviation }\end{array}$ & Minimum & Maximum \\
\hline $\begin{array}{l}\text { Dependent } \\
\text { Variable }\end{array}$ & cep & $\begin{array}{l}\text { Outward foreign direct } \\
\text { investment flows of Fujian } \\
\text { Province }\end{array}$ & 1486.453 & 1771.016 & 0 & 7442 \\
\hline \multirow{4}{*}{$\begin{array}{c}\text { Explanatory } \\
\text { Variable }\end{array}$} & fgdp & GDP of Fujian Province & 13069.54 & 7916.869 & 1.656 & 25979.82 \\
\hline & cgdp & $\begin{array}{l}\text { Gross domestic product of host } \\
\text { country }\end{array}$ & 27.54895 & 14.5147 & 1 & 47 \\
\hline & distance & Distance cost & 17.8042 & 10.50531 & 1 & 40 \\
\hline & exch & $\begin{array}{c}\text { RMB exchange rate against host } \\
\text { countries }\end{array}$ & 0.62879 & 28722.73 & 0.62879 & 28722.73 \\
\hline \multirow{4}{*}{$\begin{array}{l}\text { Control } \\
\text { Variable }\end{array}$} & coll & $\begin{array}{c}\text { Gross enrollment rate of } \\
\text { Universities }\end{array}$ & 78.13462 & 65.87077 & 1 & 200 \\
\hline & pat & $\begin{array}{c}\text { Total number of patent } \\
\text { applications }\end{array}$ & 53051.72 & 125302.1 & 0 & 589410 \\
\hline & landoff & $\begin{array}{c}\text { At least } 20 \% \text { of the population } \\
\text { use Chinese }\end{array}$ & 0.1888112 & 0.3920446 & 0 & 1 \\
\hline & colon & Is there a colonial history? & 0.8181818 & 0.3863707 & 0 & 1 \\
\hline
\end{tabular}

Table 1 Variables and statistics description

\section{Data Description}

In this paper, samples we used are selected from 22 countries or regions with direct investment relations in Fujian Province, including Australia, Brazil, Brunei, Cambodia, Canada, Honkong, India, Indonesia, Japan, Laos, Macao, Malaysia, Myanmar, Nigeria, Philippines, Russian, Singapore, South Africa, Thailand, United Kingdom, United States and Vietnam. In accordance with the close degree 
of investment, the ASEAN countries and Hongkong, Macao became the hot places of Fujian enterprises' OFDI, and then select 1-2 representative countries in all continents. The data period is $2002-2015$.

The data source of OFDI on host countries in Fujian can be divided into two parts. The data from 2002 to 2012 is reported by Chinese Ministry of Commerce, from the Statistical Bulletin of China' s Outward Foreign Direct Investment, according to China related investment in Fujian over the same period accounted for Chinese multiplied by the flow of outward foreign direct investment flow calculation. Data from 2013 to 2015 is acquired through the online applications for Fujian Provincial Department of commerce. There are also some deviations in the regression results due to the different methods of calculating the outward foreign direct investment flows in Fujian each year. GDP data from the host country comes from the WEO database in IMF, based on the October 2016 constant dollar price. GDP data in Fujian Province is from China's Ministry of the Commerce the 2009 Statistical Bulletin of China' s Outward Foreign Direct Investment and 2015 Statistical Bulletin of China' s Outward Foreign Direct Investment.The exchange rate data is derived from the exchange rate history data website of https://www.oanda.com/, using the direct quotation method, the exchange rate between RMB and the host country currency was completed on the website for 2002-2015 years. The data of colonization and language environment were derived from the CEPII database.

Based on the collection and collation of these data, through the "Stata" software regression statistics, regression results are obtained.nvestment destination, should you choose such a country or region.

\section{Regression Result and Analysis}

Through the empirical test of the model (1) (see Table2), we can find that in the significance test of the overall coefficients, the Wald values are higher than 10, indicating that the conclusions are credibility relative to the overall coefficients. The influence of the main explanatory variables is embodied in the following: first, the coefficient of $\ln (\mathrm{fgdp})$ (Fujian Province GDP) is positive and robust. By robustness test,we find that the values are stable at about 1.64. This shows that the economic scale of Fujian province has a positive and steady influence on the foreign direct investment of Fujian Enterprises. With the continuous improvement of Fujian's economic strength and the rising prices of domestic production factors, more and more enterprises need to allocate resources around the world, and the demand for foreign direct investment will continue to increase.

Second, the impact of GDP on the positive and negative effects of OFDI is uncertain, depending on the type of OFDI[12]. From the empirical test the indication can be seen in the ln (cgdp) (GDP of host country) coefficient, which is negative and not obvious in significant. This shows that the host country market is inversely related to the OFDI of Fujian enterprises, and the impact is not significant. The OFDI of Fujian enterprises is not typical market seeking type. This can be interpreted as determining the direct foreign investment of Fujian enterprises, not only because of the size of the host country's economic market, but also more likely to take into account the similarity of regional culture and economic level of the host country or region [14]. It can also be understood that the motivation of Fujian enterprises OFDI to seek market in developed countries is not obvious.

Third, because of the negative impact of cost on OFDI, $\ln$ (distance) coefficient is significantly negative, that is the Fujian OFDI enterprise scale will decrease with the increase of the distance, the regional distribution of OFDI and Fujian enterprises mainly concentrated in Hongkong, Macao and Southeast Asia that is consistent. This is because the geographical distance farther, foreign direct investment, the higher the cost.

Fourth, the exchange rate of $\ln (\mathrm{exch})$ coefficient is significantly positive, indicating that trade partners of the currency devaluation, currency appreciation in Fujian province foreign direct trade volume will increase.This is mainly because the appreciation of the local currency, the use of local currency to buy foreign related raw materials or hire labor prices cheaper, which is conducive to enterprises to carry out foreign direct investment. 
Table 2 Results of empirical analysis

\begin{tabular}{|c|c|c|c|c|}
\hline & Equation 1 & Equation 2 & Equation 3 & Equation 4 \\
\hline \multirow{2}{*}{$\ln (f g d p)$} & $1.657122^{* *}$ & $1.636687^{* * *}$ & $1.635653^{* * *}$ & $1.637553^{* * *}$ \\
\hline & $(-12.45)$ & (13.07) & (15.96) & $\left(13.54_{-}\right.$ \\
\hline \multirow{2}{*}{$\ln (\operatorname{cgdp})$} & -0.0994105 & $-0.3404001^{* *}$ & -0.0299873 & $-0.2135878^{* *}$ \\
\hline & $(-0.84)$ & $(-2.55)$ & $(0.32)$ & $(-1.97)$ \\
\hline \multirow{2}{*}{$\ln ($ distance $)$} & $-0.1317267^{* *}$ & $-0.2601142^{* * *}$ & $-0.3274109^{* * *}$ & $-0.1046233^{*}$ \\
\hline & $(-2.31)$ & $(-4.64)$ & $(5.25)$ & $(-1.93)$ \\
\hline \multirow{2}{*}{$\ln ($ exch $)$} & $0.0802773^{* * *}$ & $0.1555179^{* * *}$ & $0.1603102^{* * *}$ & $0.0839535^{* * *}$ \\
\hline & $(3.83)$ & $(6.09)$ & $(7.86)$ & $(3.67)$ \\
\hline \multirow{2}{*}{$\ln ($ coll $)$} & $0.075553^{*}$ & & & \\
\hline & $(1.83)$ & & & \\
\hline \multirow{2}{*}{$\ln$ (pat) } & & $0.1308919^{* * *}$ & & \\
\hline & & $(3.75)$ & & \\
\hline \multirow{2}{*}{$\ln$ (landoff) } & & & $2.158323^{* * *}$ & \\
\hline & & & $(8.66)$ & \\
\hline \multirow{2}{*}{$\ln ($ colon $)$} & & & & $0.2791195^{* * *}$ \\
\hline & & & & $(-8.06)$ \\
\hline Sample size & 247 & 247 & 272 & 271 \\
\hline Wald & 47.78 & 183.62 & 93.47 & 20.57 \\
\hline
\end{tabular}

Note: the value in bracket is $\mathrm{Z}, * * *$ significant at $1 \%, * *$ significant at $5 \%$ and $*$ significant at $10 \%$. Wald test, if the Wald value is greater than 10 , it shows that the overall coefficient is significant.

To determine whether the results obtained are robust, this paper conducts regression analysis by adding four control variables, coll (University gross enrollment rate), pat (total patent applications), landoff (language environment) and colon (colonial history).After join the 'coll' and 'pat' variables, confidence level in $10 \%$ and $1 \%$ is significantly positive. That is to said Fujian enterprises have not blindly seeking the advantage of labor force in the process of foreign direct investment, high-tech talent advantage and also the influence factors of enterprises in Fujian OFDI. For example, in 2013, the new Holland history computer Limited by Share Ltd will gain the acquisition of the holding company in Taiwan Teape Technology Co., Ltd. 58\% stake in the price of 280 thousand euro. After adding landoff (whether to use Chinese), the coefficient is positive and the confidence level is $1 \%$. It shows that the convergence of language and culture in a region where Chinese used more is attractive for Fujian enterprises to invest directly. Join the colon (whether colonial history) coefficient is significantly positive, that the special historical reason makes the opening degree of a colonial country or region is relatively high, more open to foreign investment enterprises in Fujian, OFDI was influenced by it. When controlling the four variables of coll, pat, landoff and colon respectively, the coefficients of three explanatory variables, fgdp, distance and exch, are still robust, and the conclusion is reliable. 


\section{Conclusion}

Based on the data of 2002-2015 enterprises's outward FDI in 22 countries or regions in Fujian, this paper examines the influence factors of FDI in Fujian enterprises based on the investment gravity model. In summary, using the gravity model analysis of outward foreign direct investment of Fujian enterprise data, respectively in the control of coll, pat, landoff and colon of the four variables, fgdp, distance, exch coefficient three explanatory variables are robust, shows that the economic development of Fujian Province has a significant positive impact on the enterprises in Fujian, the outward foreign direct investment of Fujian enterprises are their own developing needs under the impact of globalization; distance factors have a negative impact on enterprises in Fujian OFDI, Fujian enterprises more inclined to adjacent areas of investment; the appreciation of the local exchange rate makes the purchasing power of RMB improve, is conducive to increasing outward foreign direct investment; Fujian enterprises have clear strategic resources seeking motivation; the language environment created by the use of Chinese and the openness caused by colonial history are also related to the location choice of Fujian enterprises OFDI.

Fujian enterprise OFDI model is not yet mature, this requires the joint efforts of enterprises and local governments. Recommendations are including two aspects, both to enterprises themselves action, but also to the government through administrative means to build a service platform for enterprises to solve the problem.

\section{Acknowledgements}

This work was financially supported by the Foundation of Planning of the Social Sciences in Fujian Province(FJ2016C143),

\section{References}

[1] Anderson,J.The Theoretical Foundation for the Gravity Equation[J]. American Economic Review. 1979, 93(01): 106-116.

[2] Buckley,Clegg, Cross, Voss, and Zhang.The Determination of Chinese Outward Foreign Direct Investment[J]. Journal of International Business Studies. 1999, (160):113-124.

[3] Cassey Lee, Chew Ging Lee and Michael Yeo. Determinants of Singapore's Outward FDI[J]. Journal of Southeast Asian Economies.2016, 33(01): 23-40.

[4] Li Hongjie, Gou Maolan, Zhang Xuhua.The Development of Outward Foreign Direct Investment in Fujian Province and Its Policy Choice[J].Asia-Pacific Economy. 2014, (06): 114-118.

[5] Wenwen Lu. Analysis of Fujian's Outward Foreign Direct Investment[J].International Engineering and Services. 2015, (04): 98-99.

[6] Wenwen Lu. The Present Situation, Characteristics and Function Analysis of Fujian Outwatd Foreign Direct Investment[J].Technology and Industry. 2016, 16(10): 79-83.

[7] Wenbin Chen . Motivation Analysis and Mode Choice of China's Outward Foreign Direct Investment -- Taking Fujian Province as an example[J].Time Finance. 2008, (04):170-171.

[8] Yi Long Jun, Hu Ridong. Innovation Strategy of Fujian Enterprises' Overseas Direct Investment[J].Journal of Guizhou University of Technology.2006, 08(01):16-19. 